\title{
COLOR STABILITY AND SURFACE ROUGHNESS OF AN ORGANICALLY MODIFIED CERAMIC (ORMOCER) AND A METHACRYLATE BASED COMPOSITE RESINS (AN IN-VITRO STUDY)
}

\author{
Ramy M. Sherif ${ }^{* *} B D S$, Wegdan M. Abd El-Fattah ${ }^{2} P h D$, Rania R. Afifi ${ }^{3} P h D$
}

\begin{abstract}
INTRODUCTION: Any esthetic restorative material largely depends on the color match and the color stability of the material in long term use. Also the smooth surface appear to be critical for composite performance and it's aesthetic outcome. However resin composites are materials that can show color changing when exposed to staining media.

OBJECTIVES: The aim of this invitro study is to evaluate the color stability, change in opacity and change in surface roughness of an ORMOCER, and two methacrylate based composites after being immersed in different staining solutions with different time intervals.

MATERIALS AND METHODS: A total of one hundred twenty disc specimens (10 $\mathrm{mm}$ in diameter and $2 \mathrm{~mm}$ in thickness) were prepared from three composite resins, A bulk fill ORMOCER based (Admira fusion X-tra) and a bulk fill methacrylate based (X-tra fill) and an incremental fill methacrylate based (Esthet-X HD) composite resins $(n=40)$. Specimens of each type were divided in to four groups according to immersion solutions $(\mathrm{n}=10)$. Group $\mathrm{A}=$ Specimens were immersed in coffee (Nescafe classic, Nestle, Egypt), Group $\mathrm{B}=\mathrm{Specimen}$ were immersed in tea (Lipton yellow lable, Unilever brand, Egypt), Group C = Specimen were immersed in cola (Coca cola company, Egypt) and Group $\mathrm{D}=$ Specimen were immersed in distilled water as a control group. Color evaluation was done at base line before staining and then at periods of 7 days, 14 days, 28 days using spectrophotometer. Change in color $\left(\Delta \mathrm{E}^{*}\right)$ and opacity $(\Delta \mathrm{Op})$ were obtained using the CIE $\mathrm{L}^{*} \mathrm{a}^{*} \mathrm{~b}^{*}$ system. Surface roughness was evaluated using Atomic Force microscopy at baseline before staining and then at 28 days from immersion in staining solutions.
\end{abstract}

RESULTS: All composite used showed change in color values at the end of the time intervals after 28 days of immersion in staining solutions. Group A (coffee) was the highest effecting group $(\Delta \mathrm{E}>3.3)$ and Admira fusion $\mathrm{X}$ tra was the material with the highest change in color. Surface roughness also increased especially in group C (cola) for all materials after 28 days with no statistically significant difference between groups $(\mathrm{p}>0.05)$.

CONCLUSIONS: Coffee has a higher effect on staining composite resin than tea and cola. While cola affected the surface roughness of the composite resins used more than the other solution used.

KEYWORDS: Color change, Surface roughness, ORMOCR, Atomic force microscopy.

1- BDS, Faculty of Dentistry, 6th October University.

2- Professor of Conservative Dentistry, Faculty of Dentistry, Alexandria University

3- Lecturer of Conservative Dentistry, Faculty of Dentistry, Alexandria University.

*Corresponding author:

E-mail: ramydentist84@yahoo.com

\section{INTRODUCTION}

Resin composites have been the most popular material in aesthetic dentistry since they were first described in the 1960s. Aesthetic restorative materials should resembles the appearance of the natural tooth in both color match and color stability (1). Since their introduction in the dental market, their monomer chemistry, filler type, number and structure have been continuously developed to improve their chemical and physical properties (2).

Color is one of the most important attributes of aesthetic restorations. Matrix, filler content, pigment addition, and initiation components affect the color of aesthetic materials. The interactions of each of these components may have a role in the color stability of the material, as well as the dimension of the filler particles, depth of polymerization and coloring agents (3). Color change in resin restorations may be due to intrinsic and extrinsic staining. Intrinsic factors, such as changes in the filler, matrix or saline coating, while extrinsic factors, as absorption of stains, incomplete polymerization, chemical reactivity, diet and oral hygiene may cause discoloration of aesthetic materials (4).
Surface texture of dental materials has a major influence on plaque accumulation, discoloration, wear and esthetic appearance of direct and indirect restoration. The roughness of tooth structure and restorative materials affects the retention of microorganisms. The rougher surface allows the fast colonization by microorganisms and maturation of the biofilm, increasing the risk of the development of dental caries and periodontal disease as well as the susceptibility to staining of the restoration $(5,6)$.

Recently, bulk-fill resin-based composites with flowable and high-viscosity types have been popular now due to the easy application technique unlike the conventional resin composites they can be inserted with 4 $\mathrm{mm}$ single layer. When trying to optimize the properties of the material, manufacturers incorporated a new advanced composite filler technologies by reducing the filler content to facilitate deeper light transmission, increasing particle sizes to improve the mechanical strength, highly lightreactive photo initiator systems (7). In addition, modifications in the resin matrix have been done as (ORMOCER) which is an abbreviation for Organically Modified Ceramics. Initially they were used together with 
dimethacrylates, but recently a new bulk fill material with a pure-ormocer-based resin matrix has been developed. The main characteristic of this type of material is the incorporation of organic groups linked to the inorganic backbone in addition to the inorganic silanated filler particles in a nanoscopic scale $(8,9)$.

In our work color change for the ormocer and methacrylate-based composites due to staining was measured with spectrophotometers, Using CIE L* $\mathrm{a}^{*} \mathrm{~b}^{*}$ color system. While Surface roughness was measured by using atomic force microscopy which has been largely used in dentistry to study surface characteristics of different materials $(10,11)$.

The null hypothesis of this study was that there would be no differences in color, opacity and surface roughness of a bulk fill ORMOCR and methacrylate- based composite after immersion in different staining solutions at different time intervals.

\section{MATERIALS AND METHODS}

This study was conducted on a bulk fill ORMOCER based (Admira fusion X-tra, Voco $\mathrm{GmbH}$, cuxhaven, Germany) and a bulk fill methacrylate based (X-tra fill, Voco GmbH, cuxhaven, Germany) and an incremental fill methacrylate based (Esthet-X HD, Dentsply Caulk, USA) composite resins. Fourty discs for each type of composite with universal shad giving a total of hundred and twenty disc specimens were prepared using a Split Teflon mold with dimensions of $10 \mathrm{~mm}$ diameter and a thickness of $2 \mathrm{~mm}$.

A glass slide $1 \mathrm{~mm}$ thickness was placed and the Teflon mold was placed over it the material was packed inside the mold until it was slightly overfilled. Then a mylar strip was placed over the composite resin and another glass slide, was slightly compressed to extrude excess material. Curing was performed by positioning the light guide tip to be in contact with the glass slide on the top surface using a LED light curing unit (LEDB, WOODPECKER, CHINA) (1400 $\mathrm{mw} / \mathrm{cm} 2$ ) for 20sec. according to the manufacturer's instructions. Then specimens were finished using POGO one step diamond Micro -Polisher (Dentsply Caulk, USA). After polymerization, the specimens were stored in distilled water at $37^{\circ} \mathrm{C}$ for $24 \mathrm{~h}$ for rehydration and completion of polymerization (1).

The forty specimens per each group of restorative material were divided into four groups according to immersion solutions as follows $(n=10)$ : Group A: Ten specimens from each group with a total of 30 specimens were immersed in $37^{\circ} \mathrm{C}$ coffee (Nescafe classic, Nestle, Egypt) $15 \mathrm{~g}$ of coffee powder dissolved in $200 \mathrm{ml}$ boiling water (12). Group B: Ten specimens from each group with a total of 30 specimens were immersed in $37^{\circ} \mathrm{C}$ tea (Lipton, yellow lable, Unilever brand, Egypt) prefabricated tea bag will be immersed in $150 \mathrm{ml}$ of boiling water for $5 \mathrm{~min}$ (1). Group C: Ten specimens from each group with a total of 30 specimens were immersed in $37^{\circ} \mathrm{C}$ coka cola (Coca cola company, Egypt). Group D: Ten specimens from each group with a total of 30 specimens were immersed in $37^{\circ} \mathrm{C}$ distilled water as control group.

The color of all specimens was evaluated at baseline (T0) before immersion in solutions using spectrophotometer (SP60, X-Rite, Grand Rapids, USA). Then the specimens in each group were reevaluated for color change according to three time intervals, 7 days (T1), 14 days (T2) and 28 days (T3) after immersion. Immersion solutions were renewed every 2 days to avoid bacteria or yeast contamination $(13,14)$.

The color parameters CIE LAB ( $\mathrm{L}^{*}, \mathrm{a}^{*}$ and $\left.\mathrm{b}^{*}\right)$ used in this study. According to the CIE L*a*b* color coordination system, it quantifies the color in terms of three coordinate values $L^{*}, a^{*}$ and $b^{*}$. Where $L^{*}$ represents brightness or lightness (value), $\mathrm{a}^{*}$ and $\mathrm{b}^{*}$ represents for hue and chroma respectively. $\Delta \mathrm{E}$ is calculated by formula

$\Delta \mathrm{E}=\left[\left(\Delta \mathrm{L}^{*}\right) 2+\left(\Delta \mathrm{b}^{*}\right) 2+\left(\Delta \mathrm{a}^{*}\right) 2\right] 1 / 2 .(15,16)$

$\Delta \mathrm{L}^{*}=\mathrm{L}^{*}(\mathrm{tx})-\mathrm{L} *(\mathrm{t} 0)$, where $(\mathrm{tx})$ represents immersion time and $(\mathrm{t} 0)$ the baseline.

The opacity parameter (op) was determined as a percentage of $\mathrm{L}^{*}$ values, obtained from the measurements on the calibration reference of the spectrophotometer consists of a white background and another place for a black background before and after immersion in different staining solution according to following equation:

$O p=\frac{L^{*} \text { blackbackground }}{L^{*} \text { whitebackground }} \times 100 \cdot(16)$

\section{Surface roughness measurement:}

Atomic Force Microscope (Veeco Co, USA) was used to measure the surface roughness of a representative samples $(n=20)$ from the hole of $(n=40)$ of each composite resin before and after immersion in the staining solutions. Atomic Force Microscopy (AFM) gave 3-D images and microroughness $(\mathrm{Ra})$ for all groups. (11)

The surface of the composite specimen was cleaned to ensure accurate and consistent readings. The surface roughness for each specimen was determined before immersion ( $\mathrm{t} 0$ ), then, the test was performed again after 28 days. The readings for each specimen was taken and the average was calculated in nanometers. Thus, a high value would indicate a rough surface, while; a low value would present a smooth surface.

\section{Statistical analysis:}

Data were fed to the computer using IBM SPSS (statistical package for social science) software package version 20.0.

Qualitative data were described using number and percent. Comparison between different groups regarding categorical variables was tested using Chi-square test.

Quantitative data were described using mean and standard deviation for normally distributed data while abnormally distributed data was expressed using median, minimum and maximum.

For normally distributed data, comparison more than two population were analyzed F-test (ANOVA) to be used, followed by Post Hoc test to detect the level of significant between each two groups.

\section{RESULTS}

The color changes $(\Delta \mathrm{E})$ during the course of the study for each material and staining solution represented in Figure (1) which show that after 7 days of immersion Group A (coffee) showed $(\Delta \mathrm{E}>3.3)$ values which is more than the clinically accepted values range from $(\Delta \mathrm{E}=6.47-5.12)$, then group $\mathrm{C}$ (cola) for all materials. X-tra fill was more stained with coffee than the other materials. Then after 14 days a statistically significant difference $(\mathrm{p}<0.05)$ change in color happened for all materials. Group A (coffee) then Group B (tea) became the most power staining solutions on all materials. 


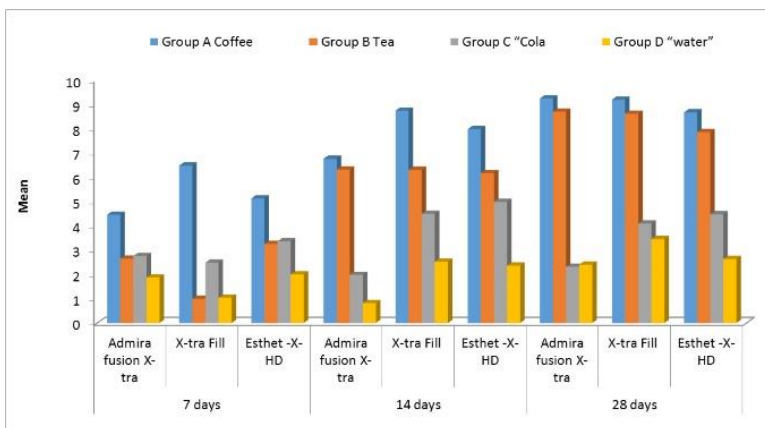

Figure (1): Comparison between $\Delta \mathrm{E}$ in different materials and group at different period of follow up.

After 28 days the mean values and standard deviations of $(\Delta \mathrm{E})$ for the materials used are shown in Table (1). Coffee then tea showed the strongest staining potential for all composites and the least staining solution was the distilled water. The material most intensively stained by coffee was Admira fusion $X-\operatorname{tra}(\Delta E=9.23)$, and tea $(\Delta E=8.69)$, while the least stained material was Esthet $\mathrm{X}-\mathrm{HD}(\Delta \mathrm{E}=8.66)$, $(\Delta \mathrm{E}=7.85)$ in coffee and tea respectively.

Table (1): The mean values and standard deviations of the color changes $(\Delta \mathrm{E})$ of the materials after 28 days of immersion in the different solutions.

\begin{tabular}{|l|c|c|c|c||}
\hline & $\begin{array}{c}\text { Admira } \\
\text { fusion X- } \\
\text { tra }\end{array}$ & X-tra Fill & $\begin{array}{c}\text { Esthet -X- } \\
\text { HD }\end{array}$ & $\begin{array}{c}\text { F } \\
\mathbf{p}\end{array}$ \\
\hline $\begin{array}{l}\text { Group A } \\
\text { Coffee }\end{array}$ & $9.23 \pm 1.15$ & $9.18 \pm 0.81$ & $8.66 \pm 0.42$ & $\begin{array}{c}3.05 \\
0.107\end{array}$ \\
\hline $\begin{array}{l}\text { Group B } \\
\text { Tea }\end{array}$ & $8.69 \pm 2.30$ & $8.60 \pm 0.60$ & $7.85 \pm 1.08$ & $\begin{array}{c}2.01 \\
0.336\end{array}$ \\
\hline $\begin{array}{l}\text { Group C } \\
\text { "Cola }\end{array}$ & $2.31 \pm 0.32$ & $4.09 \pm 0.53$ & $4.47 \pm 1.74$ & $\begin{array}{c}8.25 \\
0.01 *\end{array}$ \\
\hline $\begin{array}{l}\text { Group D } \\
\text { "water" }\end{array}$ & $2.40 \pm 0.39$ & $3.45 \pm 0.18$ & $2.63 \pm 0.15$ & $\begin{array}{c}5.26 \\
0.036 *\end{array}$ \\
\hline
\end{tabular}

Figure (2) represents the change in opacity for all materials after 28 days which showed increase in opacity with no statically significant difference $(p>0.05)$ between base line and all time intervals. Coffee was the solution with high effect on the all materials during the course of study ranged from $(\triangle \mathrm{OP}=98.22-97.11)$. there was no statically significant difference ( $\mathrm{p}>0.05)$ between materials used in any groups except in group B. Esthet X-HD was the material more affected.

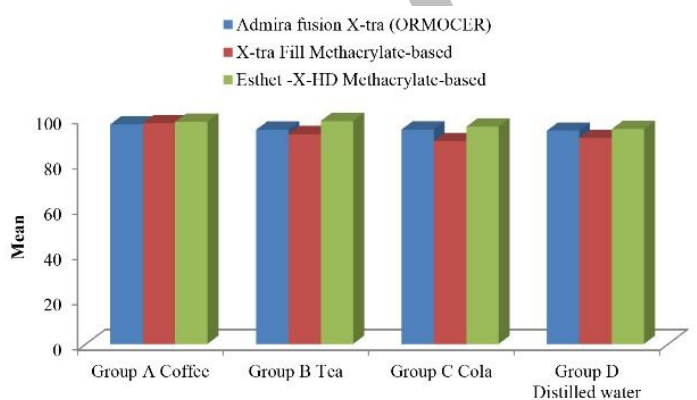

Figure (2): Comparison between opacity in different materials and group after 28 days.

\section{Surface roughness:}

In table (2), Figure (3) and 3-D images figures (4-6) represent the mean values and standard deviations of the surface roughness $(\Delta \mathrm{Ra})$ of the materials after 28 days of immersion in the different solutions, when comparing the solution groups for each composite used there was increased values of surface roughness by the end of the study with statically significant difference $(\mathrm{p}<0.05)$ for all materials. It was found that Esthet $\mathrm{X}-\mathrm{HD}$ had the highest $(\Delta \mathrm{Ra})$ value in all solutions except in distilled water. Group $\mathrm{C}$ (cola) showed the highest effect on $(\triangle \mathrm{Ra})$ of all types of composite used followed by group B (tea) with no statically significant difference $(p>0.05)$ between materials.

Table (2): Comparison between surface roughness in different groups at baseline and after 28 days of immersion in staining solutions.

\begin{tabular}{|c|c|c|c|c|}
\hline & $\begin{array}{c}\text { Admira } \\
\text { fusion X- } \\
\text { tra }\end{array}$ & X-tra Fill & $\begin{array}{c}\text { Esthet - } \\
\text { X-HD }\end{array}$ & $\begin{array}{l}\mathbf{F} \\
\mathbf{p}\end{array}$ \\
\hline Base line & $\begin{array}{c}0.040 \\
\pm 0.010\end{array}$ & $0.041 \pm 0.015$ & $\begin{array}{c}0.043 \\
\pm 0.012\end{array}$ & $\begin{array}{c}1.32 \\
0.305\end{array}$ \\
\hline $\begin{array}{l}\text { Group A } \\
\text { Coffee }\end{array}$ & $\begin{array}{c}0.051 \\
\pm 0.013\end{array}$ & $0.048 \pm 0.008$ & $\begin{array}{c}0.048 \\
\pm 0.008\end{array}$ & $\begin{array}{c}2.11 \\
0.167\end{array}$ \\
\hline $\begin{array}{l}\text { Group B } \\
\text { Tea }\end{array}$ & $\begin{array}{c}0.054 \\
\pm 0.019 \\
\end{array}$ & $0.057 \pm 0.004$ & $\begin{array}{c}0.058 \\
\pm 0.004\end{array}$ & $\begin{array}{c}2.09 \\
0.127\end{array}$ \\
\hline $\begin{array}{l}\text { Group C } \\
\text { Cola }\end{array}$ & $\begin{array}{c}0.061 \\
\pm 0.009\end{array}$ & $0.062 \pm 0.003$ & $\begin{array}{c}0.063 \\
\pm 0.003 \\
\end{array}$ & $\begin{array}{c}1.62 \\
0.365\end{array}$ \\
\hline $\begin{array}{l}\text { Group D } \\
\text { Distilled } \\
\text { water }\end{array}$ & $\begin{array}{c}0.050 \\
\pm 0.005\end{array}$ & $0.047 \pm 0.009$ & $\begin{array}{c}0.046 \\
\pm 0.011\end{array}$ & $\begin{array}{c}1.77 \\
0.412\end{array}$ \\
\hline
\end{tabular}

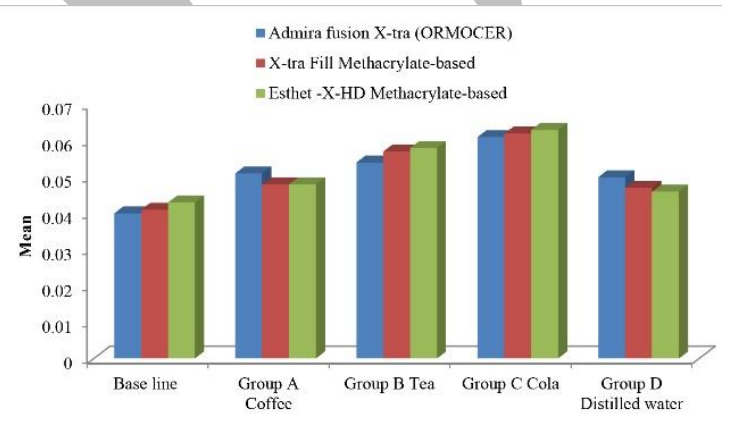

Figure (3): Comparison between surface roughness in different material in the same group at base line and after 28 days of immersion in staining solutions.
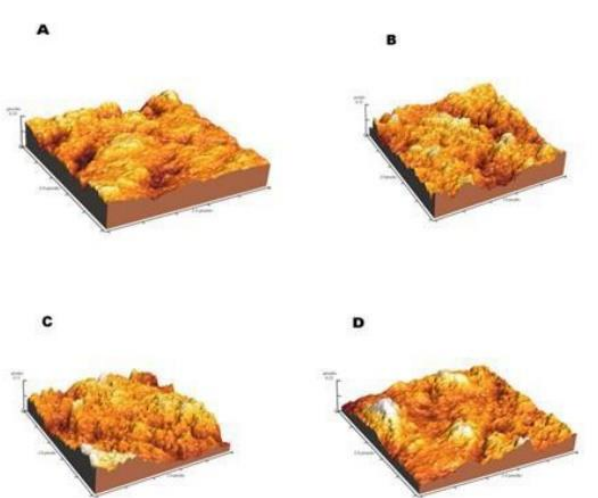

Figure (4): Admira fusion $X$ tra 3-D image of surface after staining with (A) coffee, (B) tea, (C) cola, (D) distilled water. 

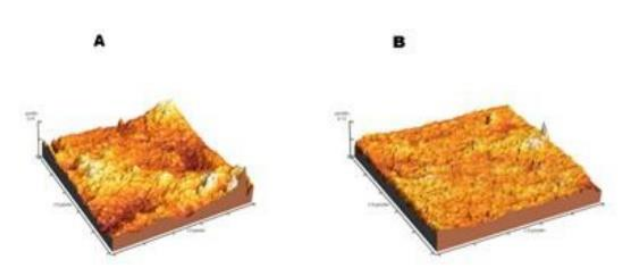

c

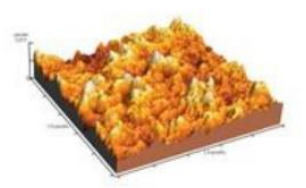

D

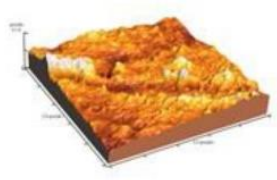

Figure (5): $X$ tra fill surface 3-D image after staining (A) coffee, (B) tea, (C) cola, (D) distilled water. c

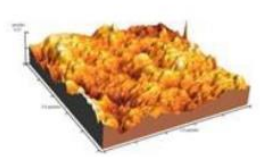

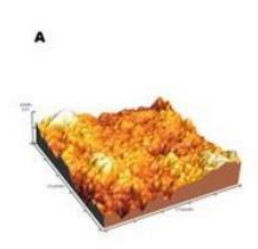

B

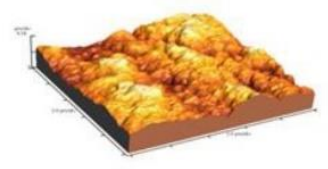

D

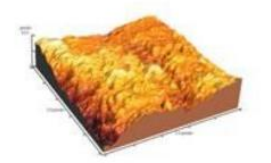

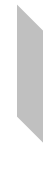

Figure (6): Esthet $\mathrm{X}-\mathrm{HD}$ surface 3-D image after staining (A) coffee, (B) tea, (C) cola, (D) distilled water.

\section{DISCUSSION}

Discoloration problem of modern composites was investigated in this study considering their susceptibility of being stained by normally consumed beverages and drinks. Different in vitro studies have demonstrated that common food substances, such as not only coffee, cola, tea but also red wine, beer and fruit juices, could cause significant change in color of composite resin materials $(17,18)$. In this study the color stability of a two methacrylate based and an ormocer composites were tested invitro after exposure to various drinks, which are commonly used. The first null hypothesis was rejected because the color parameters $(\Delta \mathrm{E})$ and $(\triangle \mathrm{OP})$ changed for all material studied. We found that Coffee presented more staining capacity range from $(\Delta \mathrm{E}=$ 8.66 - 9.23) regardless of the type of composite resin while Cola and distilled water have the least effect. The results of our study showed height change in color beyond the clinical accepted level among different groups. As reported by several authors $(\Delta \mathrm{E})$ values ranging from 1 to 3 are perceptible to the naked eye and $(\Delta \mathrm{E})$ values greater than 3.3 are clinically unacceptable $(19,20)$.

The methodology used in the present study was in accordance with previous studies that used spectrophotometry and the CIE Lab coordinate system, which is used for the determination of small color changes and has advantages of being sensitive and repeatable and recommended method for dental researches (21). The maximum immersion time in this study was 4 weeks because according to Ertas et al. (2006) (22), the average time for consumption of 1 cup of coffee is $15 \mathrm{~min}$, and among coffee drinkers, the average consumption is 3.2 cups per day, so this period is equivalent to about 2.5 years of use the minimum $24 \mathrm{~h}$ resamples in our study being equivalent to about 1 month of exposure in the mouth.

The staining susceptibility of composite resins might be due to the degree of water sorption and the hydrophilicity of the resin matrix. Composite resins can absorb water and are also able to absorb other fluids with pigments, which results in discoloration. It has been reported that water uptake in Bis-GMA-based composite resins increased from 3 to $6 \%$ as the proportion of TEGDMA increased from 0 to $1 \%$. UDMA seems to be more stain-resistant than Bis-GMA $(23,24)$. Recently ORMOCER composites were introduced contain inorganic-organic copolymers. They have threedimensionally linked inorganic-organic copolymers, additive aliphatic, and aromatic dimethacrylates with a small amount of organic resin compared with conventional BisGMA or other methacrylate-based composites (25), However, in our study, Admira fusion $X$ tra showed the highest discoloration. Which was in agreement with Gregor et al. (2016) (26) and Llena et al. (2017) (27), when evaluated the color stability of two (ormocers) composites with other types of composites following their immersion in commonly used drinks found also that the ormocer-based material had a strong discoloration potential. However, Ormocer composite reported significantly less $(\Delta \mathrm{E})$ values after exposure to coffee comparing to other tested composites by Alexandre L.S. Borges et al in (2011) (28) and Ceci, et al (2017) (29), when studied the susceptibility of restorative materials to staining by common beverages which is not in accordance with this study.

Our results showed that coffee has high capacity of staining on composite resins used which was in accordance with previous studies done by Mundim FM et al (2010) (30), Tania mara da silva et al (2017) (31) and Macedo et al (2018) (32), which demonstrated that certain substances as coffee may cause more severe staining than others. The discrepancies between these studies may be explained by the differences in experimental methodologies, types and concentration of solutions used, and restorative materials used.

Evaluation of the surface roughness is relevant to the study of composite restoration since the morphology of the surface affects the susceptibility to discoloration. The surface degradation of RBCs were associated with the acidity and the $\mathrm{pH}$ of the surrounding media, which corresponds to many previous studies that shown acids might change the physical properties of RBCs under acidic conditions over time (33-35). In our study the second null hypothesis has been rejected because the immersion in the tested solutions had an influence on increasing the specimens' surface roughness; however, there were statistical differences between the baseline, coffee, tea, cola and distilled water at the end of the study in the same material but no statistical significant difference between the three types of composites used. Although both cola and coffee had low $\mathrm{pH}$, but cola affected the roughness of the tested composite resin more than coffee. This may have been because cola is a carbonate beverage containing carbonic acid and phosphoric acid which promotes dissolution and easily eroded the materials (36). 
This study results showed that cola has the highest effect comparing to all solutions used on all composites which was in accordance with studies done by Dos Santos, et al. (2010) (37) and Ugur Erdemir et al, (2012) (38), they found that effect of cola on the surface roughness of a restorative material was the highest which was depends on the duration of exposure time, and the composition of the material.

In contrast to our results, Aliping-Mckenz et al (2004) (39), found that Fruit juices were shown to have a greater erosive effect on tooth colored materials than cola. And also da Silva et al (2011) (40), detected significant degradation of the resin matrix with immersion in coffee, so they concluded that the consumption of coffee altered the surface roughness of the resin matrix.

The results of this study showed that the commonly used beverages may affect the color and surface roughness of RBCs. However, this study only evaluated the in vitro effects, with some limitations. Therefore, further studies are required to examine the effects of beverages in vivo.

\section{CONCLUSION}

The null hypotheses of the study were rejected. Within the limitations of this in vitro study, it can be concluded that the immersion of specimens in staining beverages caused a significant color change in all types of tested composite resins. Coffee demonstrated a higher staining potential if compared to tea or cola. Among the different materials tested, Admira fusion $\mathrm{X}$ tra composites reported the highest color variations. Also the surface roughness of all materials tested was altered by the staining solution to some degree. Cola had the great effect on surface roughness and Esthet $\mathrm{X}-\mathrm{HD}$ was the material with the highest surface roughness.

\section{CONFLICT OF INTEREST}

The authors declare that they have no conflicts of interest.

\section{REFERENCES}

1-Barutcigil Ç, Yıldız M. Intrinsic and extrinsic discoloration of dimethacrylate and silorane based composites. J Dent. 2012;40(Suppl 1):e57-63.

2-Madhysatha PS, Naik DG, Kotian R, Srikant N, Bhat KMR. Effect of staining solutions on color stability of silorane \& Methacrylate Restorative Material. Int J Biomed Sci. 2015;11:29-34.

3-Uzay KV, Ismail B, Pinar A. Color stability of bulk fill and incremental fill resin-based composites polished with aluminum-oxide impregnated disks. Restor Dent Endod. 2017;42:118-24.

4-Fontes ST, Fernández MR, de Moura CM, Meireles SS. Color stability of a nanofill composite: effect of different immersion media. J Appl Oral Sci. 2009;17:388-91.

5-Cleidiel AA L, Silvio J, Paulo H, André LF, Ticiane CF. Influence of Mechanical and Chemical Degradation in the Surface Roughness, Gloss, and Color of Microhybrid Composites. J Contemp Dent Pract. 2017;18:283-8.

6-Veena SN, Shan S, Prabeesh P, Unu S, Rajesh P. Three dimensional evaluation of surface roughness of resin composites after finishing and polishing. J Conserv Dent. 2016;19:91-5.

7-Manhart J, Hickel R Bulk-fill-composites. Modern application technique of direct composites for posterior teeth. Swiss Dent J. 2014;124:19-37
8-Poggio C, Ceci M, Beltrami R, Mirando M, Wassim J, Colombo M. Color stability of esthetic materials: aspectrophotometric analysis. Acta Biomater Odontol Scand. 2016;2: 95-101.

9-Bacchi A, Feitosa VP, da Silva Fonseca AS, Cavalcante LM, Silikas N, Schneider LF. Shrinkage, stress, and modulus of dimethacrylate, ormocer, and silorane composites. J Conserv Dent. 2015;18:384-8.

10-Seda CG, Emir YS, Neslin V, Gaye S.Color stability and surface roughness of a laboratory-processed composite resin as a function of mouthrinse. J Esthet Restor Dent. 2015;27:314-21.

11-Meena KC, Manohar BK, Rahul Bansal AH. Evaluation of surface roughness of different restorative composites after polishing using atomic force microscopy. J Conserv Dent. 2016;19:56-62.

12-Koc-Vural U, Baltacioglu I, Altinci P. Color stability of bulk-fill and incremental-fill resin based composites polished with aluminum-oxide impregnated disks. Restor Dent Endod. 2017;42:118-24.

13-Arocha MA, Mayoral JR, Lefever D, Mercade M, Basilio J, Roig M. Color stability of siloranes versus methacrylatebased composites after immersion in staining solutions. Clin Oral Investig. 2013;17:1481-7.

14-Ardu S, Braut V, Gutemberg D, Krejci I, Dietschi D, Feilzer AJ. A long-term laboratory test on staining susceptibility of esthetic composite resin materials. Quintessence Int 2010;41:695-702.

15-Maria MP, Razvan G, Laura I, Ugarte A, Rosa P, Rade D. Color and translucency in siloran-based resin composite compared to universal and nanofilled composites. J Dent. 2010;38:110-116.

16-Archegas LR, Freire A, Vieira S, Caldas DB, Souza EM. Colour stability and opacity of resin cements and flowable composites for ceramic veneer luting after accelerated ageing. J Dent. 2011;39:804-10.

17-Dias HB, Carrera ET, de Souza Rastelli AN. The influence of $\mathrm{pH}$ and chemical composition of beverages on color stability of a nanofilled composite resin. Gen Dent. 2016;64:e21-7.

18-Barutcigil Ç, Barutcigil K, €Ozarslan MM, D€undar A, Yilmaz B. Color of bulk-fill composite resin restorative materials. J Esthet Restor Dent. 2018;30:E3-8.

19-Lee YK, Powers JM. Discoloration of dental resins composites after immersion in a series of organic and chemical solutions. J Biomed Mater Res B App Biomater. 2005;73:361-7.

20-Poggio C, Beltrami R, Scribante A, Colombo M, Chiesa M. Surface discoloration of composite resins: effects of staining and bleaching. Dent Res J. 2012;9:567-73.

21-Bayindir F, Kürklü D, Yanikoğlu ND. The effect of staining solutions on the color stability of provisional prosthodontic materials. J Dent. 2012;40:e41-6.

22-Ertaş E, Güler AU, Yücel AC, Köprülü H, Güler E. Color Stability of Resin Composites after Immersion in Different Drinks. Dent Mater J. 2006;25:371-6.

23-Sideridou ID, Karabela MM. Sorption of water, ethanol or ethanol/ water solutions by light-cured dental dimethacrylate resins. Dent Mater. 2011;27:1003-10.

24-Sideridou I, Tserki V, Papanastasiou G. Study of water sorption, solubility and modulus of elasticity of light-cured dimethacrylate-based dental resins. Biomaterials. 2003;24:655-65. 
25-Bacchi A, Feitosa VP, da Silva Fonseca AS, Cavalcante LM, Silikas N, Schneider LF. Shrinkage, stress, and modulus of dimethacrylate, ormocer, and silorane composites. J Conserv Dent. 2015;18:384-87.

26- Gregor L, Krejci I, Di Bella E, Feilzer AJ, Ardu S. Silorane, ormocer, methacrylate and compomer longterm staining susceptibility using $\Delta \mathrm{E}$ and $\Delta \mathrm{E} 00$ colourdifference formulas. Odontology 2016;104:305-9.

27- Llena C, Fernandez S, Forner L. Color stability of nanohybrid resinbased composites, ormocers and compomers. Clin Oral Invest. 2017;21:1071-7.

28- Alexandre LSB, Anna KFC, Guilherme SFA, Paula CP, Alessandra B, Sigmar M. Color stability of composites: effect of immersion media. Acta Odontol Latinoam. 2011; 24:193-9.

29- Ceci M, Viola M, Rattalino D, Beltrami R, Colombo M, Poggio C. Discoloration of different esthetic restorative materials: A spectrophotometric evaluation. Eur J Dent. 2017;11:149-56.

30- Mundim FM, Garcia Lda F, Pires-de-Souza Fde C. Effect of staining solutions and repolishing on color stability of direct composites. J Appl Oral Sci. 2010;18:249-54.

31- Silva TMD, Sales ALLS, Pucci CR, Borges AB, Torres CRG. The combined effect of food-simulating solutions, brushing and staining on color stability of composite resins. Acta Biomaterialia Odontologica Scandinavica 2017;3:1-7.

32- Macedo MGFP, Volpato CAM, Henriques BAPC, Vaz PCS, Silva FS, Silva CFCL. Color stability of a bis-acryl composite resin subjected to polishing, thermocycling, intercalated baths, and immersion in different beverages. J Esthet Restor Dent. 2018;30:449-56.

33- Somayaji SK, Amalan A, Ginjupalli K. Effect of Different Acidic Beverages on Microhardness of Nanohybrid Composite, Giomer, and Microhybrid Composite. World J Dent. 2016;7:126-8.
34- Tanthanuch S, Kukiattrakoon B, Siriporananon C, Ornprasert N, Mettasitthikorn W1, Likhitpreeda S, et al. The effect of different beverages on surface hardness of nanohybrid resin composite and giomer. J Conserv Dent. 2014; 17:261-5.

35- Tantanuch S, Kukiattrakoon B, Peerasukprasert T, Chanmanee N, Chaisomboonphun P, Rodklai A. Surface roughness and erosion of nanohybrid and nanofilled resin composites after immersion in red and white wine. $\mathbf{J}$ Conserv Dent. 2016;19:51-5.

36- Wongkhantee S, Patanapiradej V, Maneenut C, Tantbirojn D. Effect of acidic food and drinks on surface hardness of enamel, dentine, and tooth-coloured filling materials. J Dent. 2006;34:214-20.

37- Dos Santos PA, Garcia PP, De Oliveira AL, Chinelatti MA, Palma-Dibb RG. Chemical and morphological features of dental composite resin: Influence of light curing units and immersion media. Microsc Res Tech. 2010;73:176-81.

38- Erdemir U, Yildiz E, Eren MM, Ozel S. Surface hardness of different restorative materials after long-term immersion in sports and energy drinks. Dent Mater J. 2012;31:729-36.

39- Aliping-Mckenzie M, Linden RWA, Nicholson JW. The effect of Coca-Cola and fruit juices on the surface hardness of glass-ionomers and compomers. J Oral Rehabil. 2004;31:1046-52.

40- da Silva MA, Fardin A, de Vasconcellos RC, Santos Lde M, Tonholo J,da Silva JG Jr, et al. Analysis of roughness and surface hardness of a dental composite using atomic force microscopy and microhardness testing. Microsc Microanal. 2011;17:446-51. 